Figure S1 (con't)

\section{E. F3_gag}

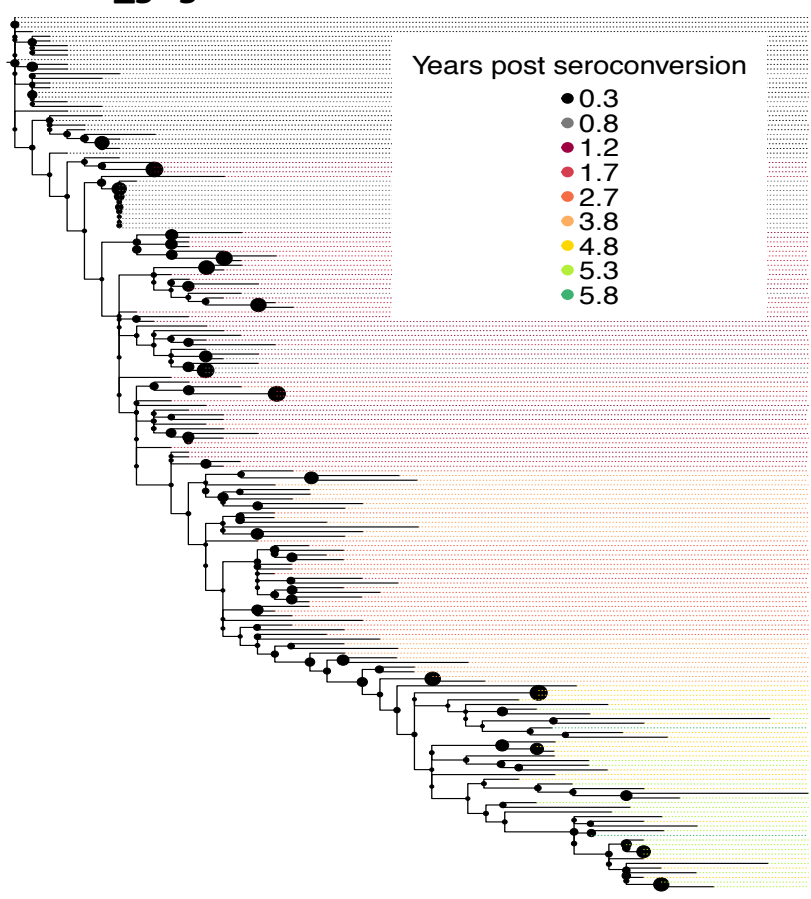

\section{G. F4_gag}

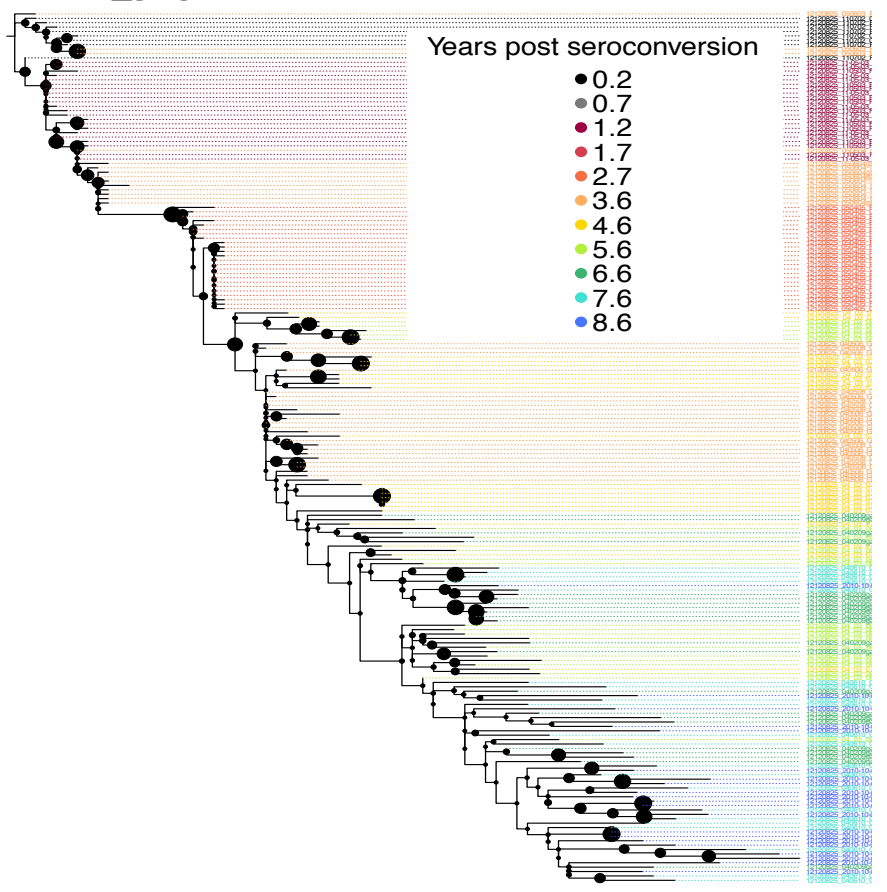

\section{F. F3_env-gp120}

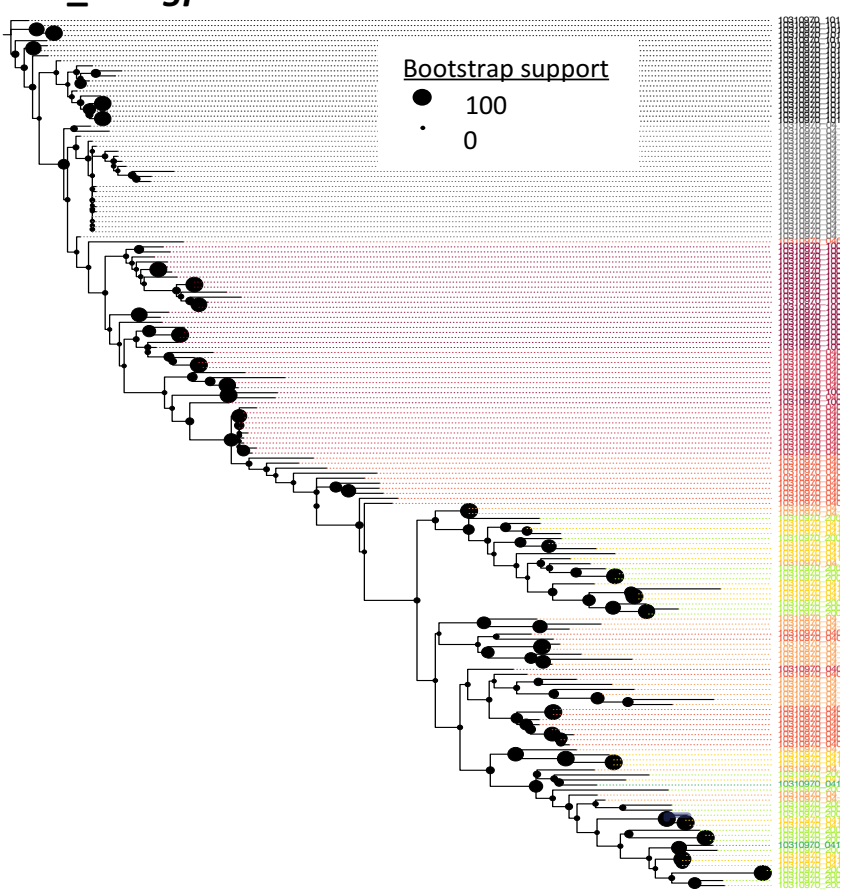

H. F4_env-gp120

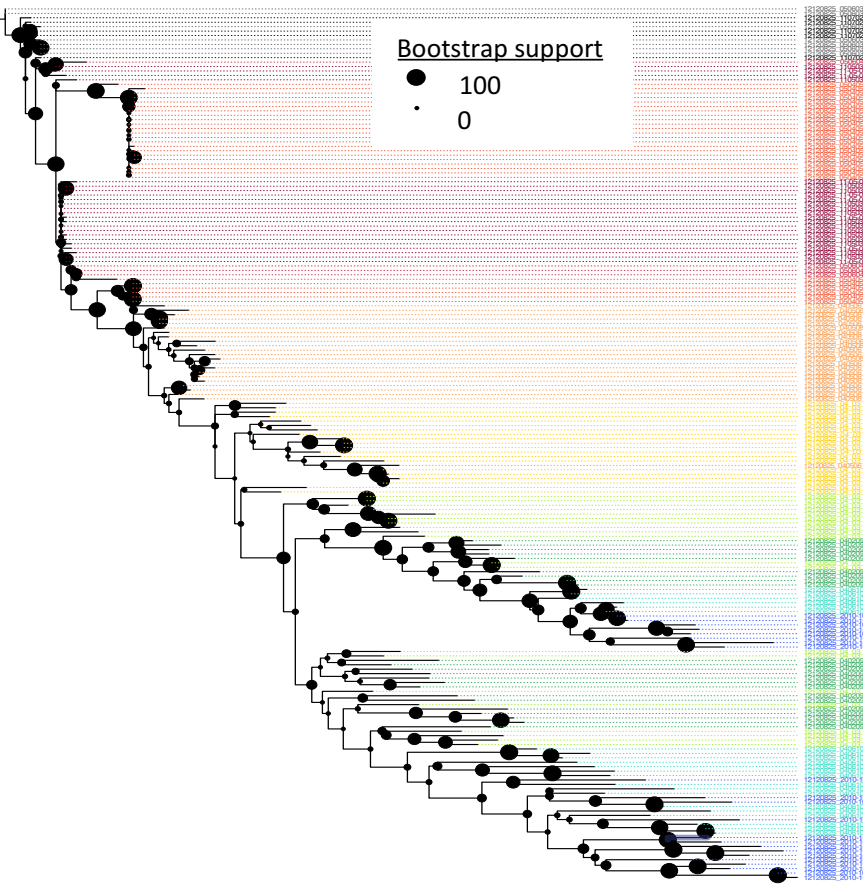


Figure S1 (con't)

\section{F5_gag}

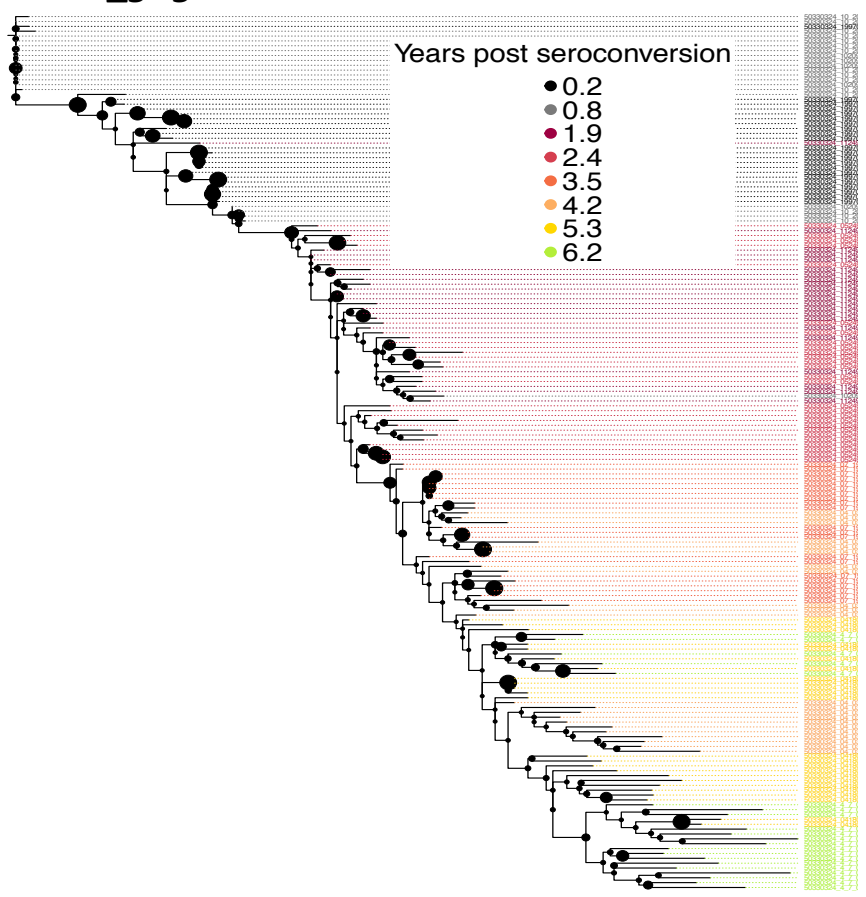

\section{K. F6_gag}

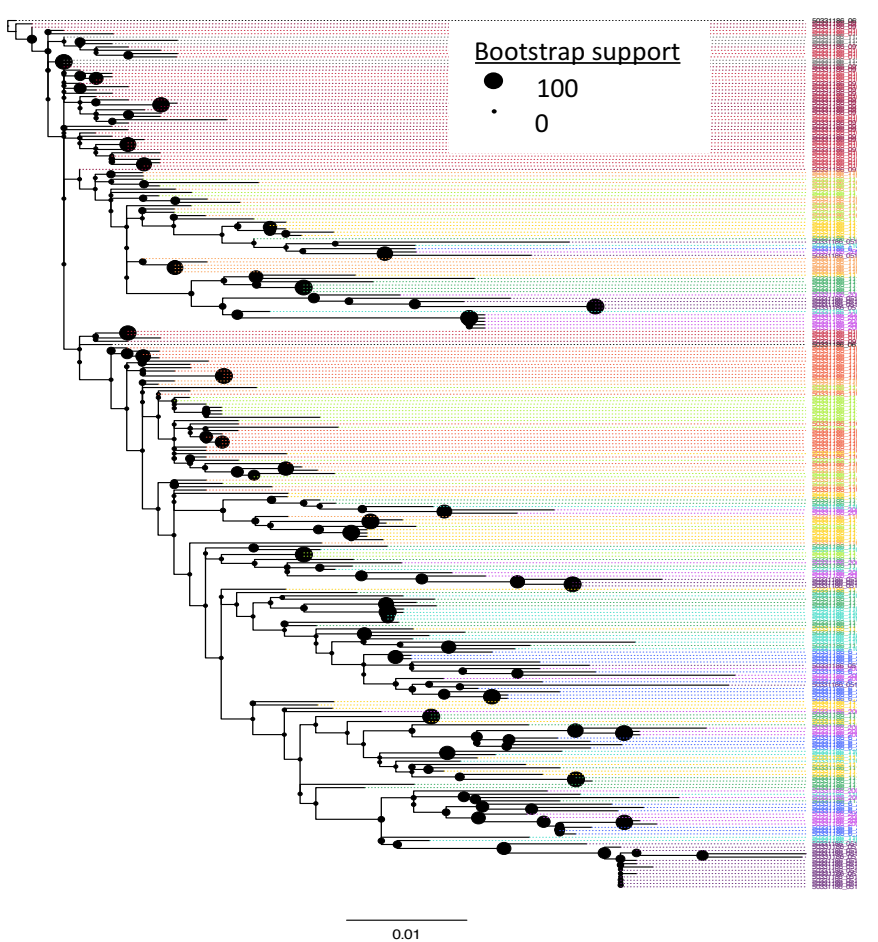

\section{J. F5_env-gp120}

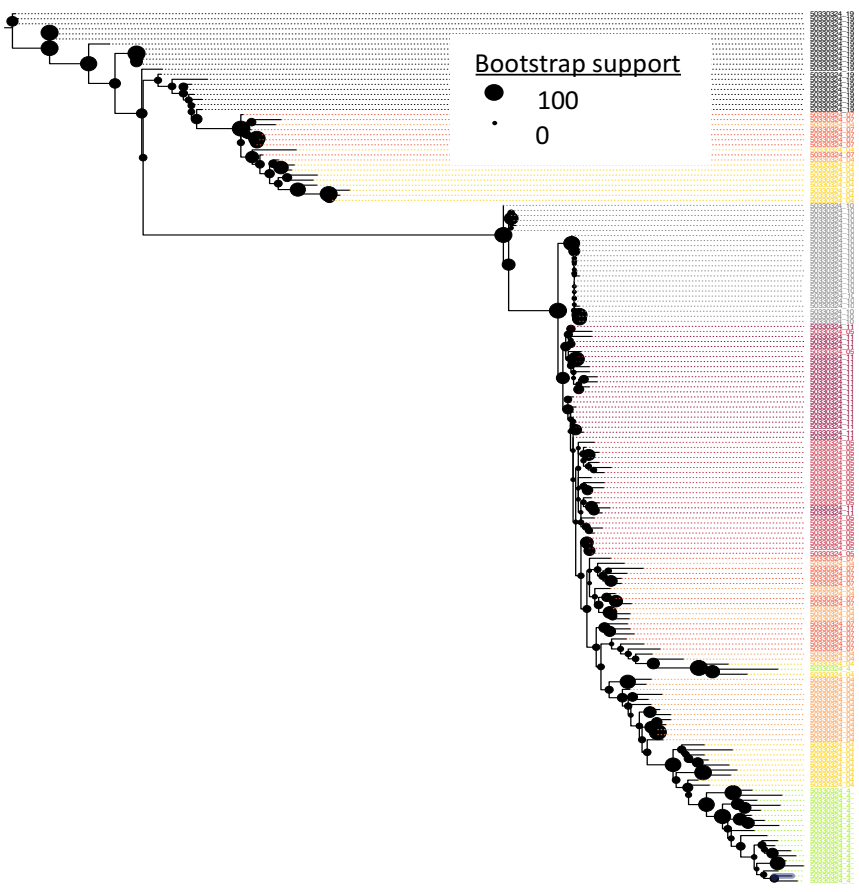

$\overline{0.01}$

\section{F6_env-gp120}

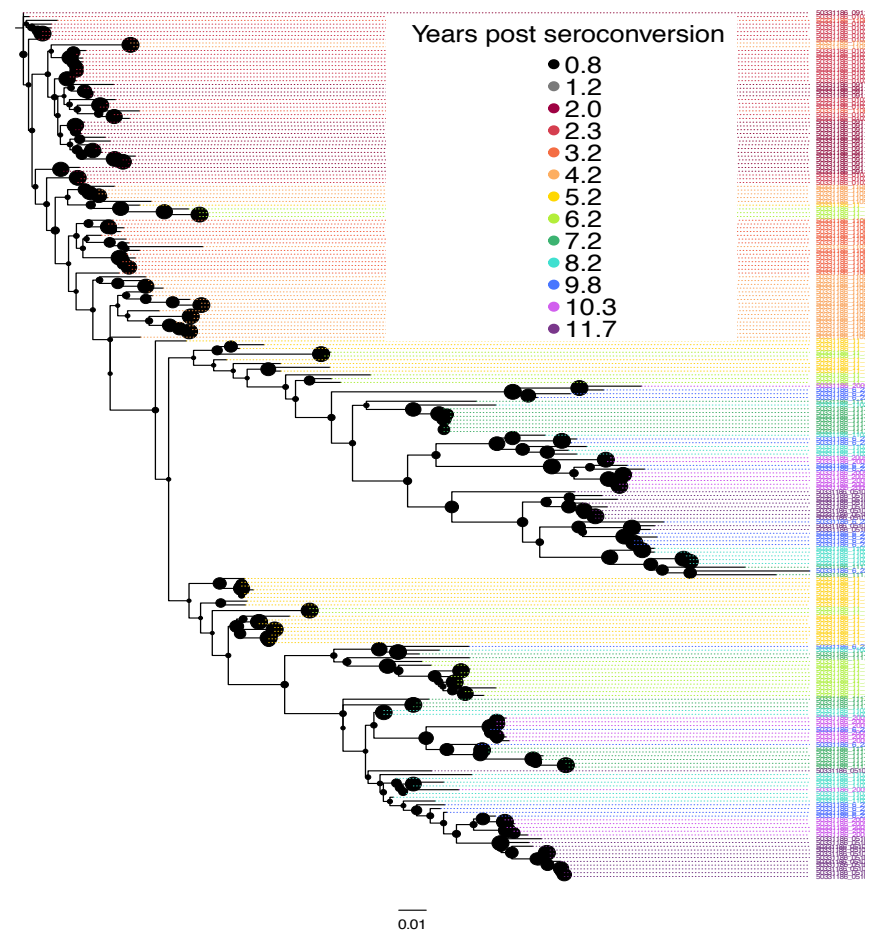


Figure S1 (con't)

M. F7_gag

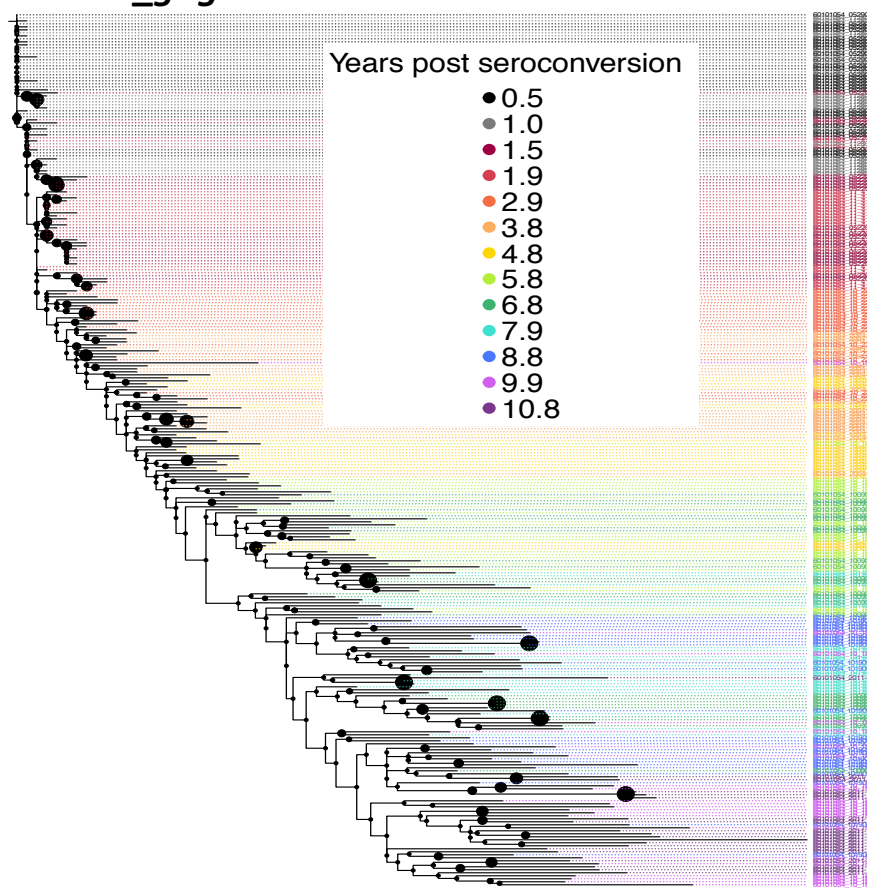

0. F8_gag

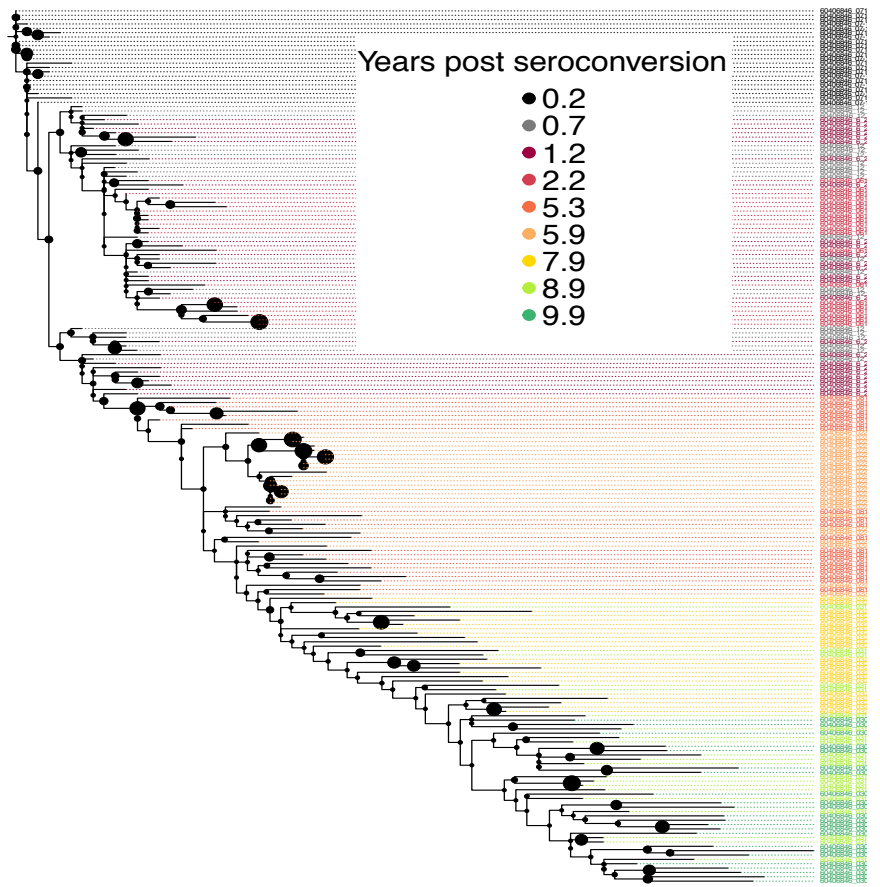

N. F7_env-gp120

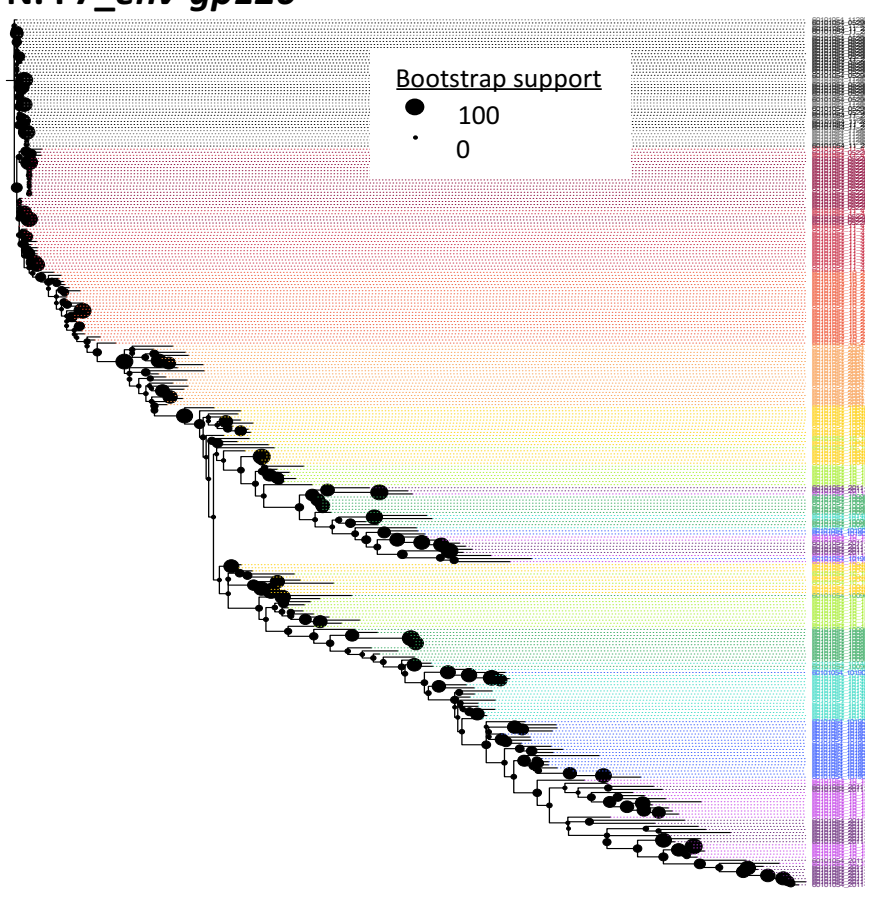

$\overline{0.01}$

\section{P. F8_env-gp120}

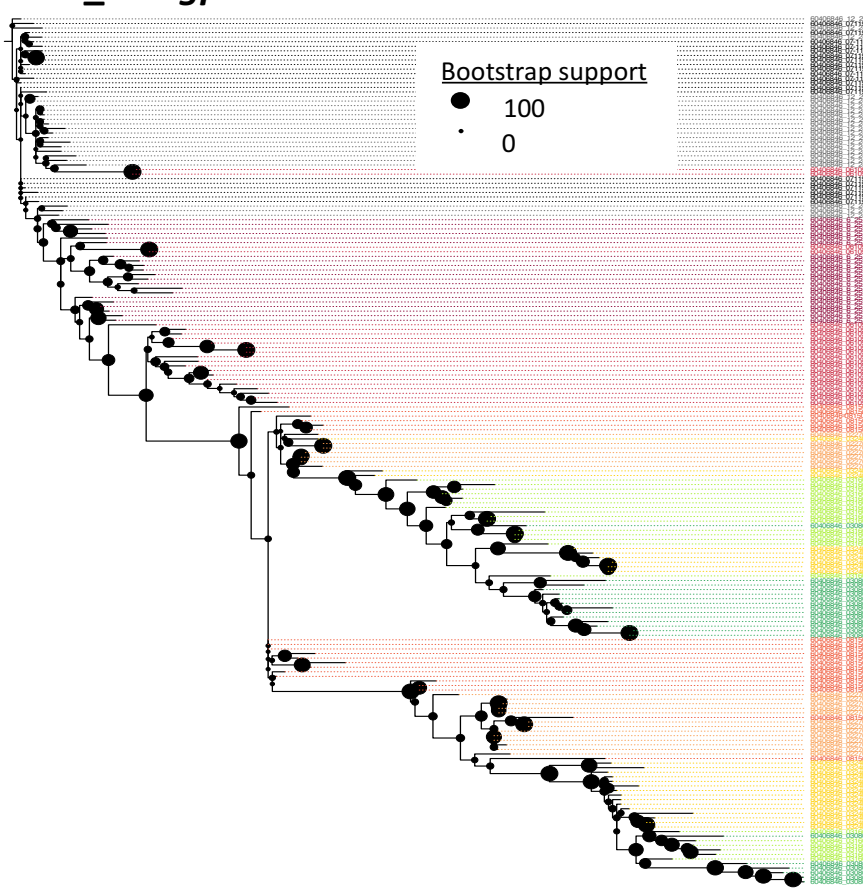

